\title{
Individual Cow Recording and Analysis System for Small Scale Dairy Farmers in Malaysia
}

\author{
Vickneswaran Jeyabalan \\ Research\&Development Division, \\ Maxvet Enterprise \\ Selangor, Malaysia
}

\begin{abstract}
A noteworthy point in the development of the dairy industry is proper record keeping. Record keeping improves a farmer's decision making significantly, as errors are eradicated and saves the farm's vital scarce resource, mainly over time. In this paper, a new computerized recording system platform with the name of Individual Cow Recording and Analysis System (ICRAS $\odot$ ) is introduced for the usage of small scale dairy farmers in Malaysia. ICRAS $\odot$ was designed by Maxvet Enterprise with the idea of simplicity, where it can be used and deployed cost effectively by farmers while providing key decision making information for improvements of their herd. The system was designed using existing and commonly used platform such as the Microsoft Excel 2003 and Visual Basic. The introduction of this system provides a new approach in the record keeping method among small scale dairy farmers in Malaysia.
\end{abstract}

\section{Keywords}

Dairy recording system, small scale dairy farming, dairy production record, fertility record, health record.

\section{INTRODUCTION}

The demand of milk and dairy products in Malaysia are in rise over the recent years due to the increase of population and changes in eating habits. The total consumption of milk by Malaysians in 2008 was around 1179.12 million litres [1] and increasing yearly. Whereas, the total milk produced locally in the same year was 56.48 million litres [1], which means that only $5 \%$ of the total consumption is produced locally. Whereby, the remaining $95 \%$ of the total consumption is being imported from countries like Australia and New Zealand. Malaysia has been striving towards the development of the dairy industry since 1978 under the implementation of the New Economic Policy with emphasis to increase the milk production of small scale dairy farmers around the country [2]. Many rigorous efforts were and are being taken by the government to boost the dairy sector. One of the latest efforts was by developing a hightech dairy operation in the East-Coast state of Pahang with the capacity of producing 19,000-22,000 liters of milk per day [3]. Apart from that, incentives in terms of livestock, facilities and machineries were also given to dairy farmers in order to increase the milk productivity [4]

There has been growing interest in small scale dairying since the 1980s all over south East Asia. In Malaysia, there around 693 dairy farmers where $84 \%$ of them are small scale farmers, whereas $9 \%$ and $8 \%$ are semi-commercial and commercial farmers respectively [4]. The small scale farmers contributed around $47.2 \%$ of the total production in the year
2008 [4]. In order to further increase the productivity of the small scale farmers, proper management practice is needed. The most important management tool is proper record keeping [5]. The ultimate purpose of a recording system is to improve the level of herd performance by achieving things better, running the farm more competently, or reducing the possibility of poor future performances. Studies have shown that, the efficiency of milk production can be increased through the practice of using a simple, precise, understandable and easy to maintain recording system [6].

In Malaysia, many small scale dairy farms, with less than 30 dairy animals are still using hand written record books and even some fail to have any records. In a manual recording system, it is usually time consuming and tedious to find important data and to make any decisions. Thus, a farmer usually takes less effort to analyze and to use its results for further action.

Information Technology (IT) systems in the Dairy industry are becoming a necessary requirement accompanied by the advancements of science and technology. Therefore, many computerized dairy recording systems were developed and have been applied in large dairy farms. But the utilization of a computerized recording system by small scale farmers is very rare and not given the priority. Among the main reasons for the lack of usage are due to the cost of buying the system which is expensive, complexity of the program, and the level of computer literacy, where this constraint appeared to be important during the 90s [7], but it is now less significant given the current trend of computer education being introduced as early as in pre-schools, initiatives from the government by the introduction of Computer Literacy Programs [8]and reduction in the cost of obtaining computers and related peripherals.

So, in order to increase the usage of a computerized recording system among the small scale dairy farmers in Malaysia, this paper proposes a simple, low cost and easy to use computerized recording system framework. This framework is hereon referred as, Individual Cow Recording and Analysis System (ICRAS@). This framework was initially designed for a farm of 2 to 30 cows since the target users are small scale farmers. However, it has also the capability to capacitate records of bigger farms with more than 100 cows. ICRAS $\odot$ was designed based on four core elements that a dairy record should have. These elements were divided into four main modules, which are the current farm statistics, herd fertility management, herd health management and individual cow records. This framework was designed with the flexibility for farmers to add customized modules and features according to their future needs. This system was developed using the waterfall model approach. 


\section{SYSTEM ANALYSIS AND DESIGN}

Dairy management softwares can be categorized into three different types: a simple event and record display program, a fully-featured management program and an integrated management program [9]. A simple event and record display program is designed to just keep and view the records. Whereas, the fully-featured management program, does not only keep records, but also analyzes them. While the integrated management program, is a full-featured management program that is incorporated with real time sensors and monitors such as milk flow meters and feeding systems. These sensors and monitors then send the information about milk production and feeding patterns of individual cows or herd to the recording system. In this paper, ICRAS $\odot$ was designed using the fullyfeatured management program approach.

ICRAS $\odot$ was developed using the Waterfall software development life cycle model. This model was chosen due to its linear approach which can be implemented easily and effectively in software development [10]. With the waterfall model, the activities performed in the development of ICRAS $($ ) were requirements analysis, planning, system designing, coding, system integration and testing. Figure 1 depicts these phases.

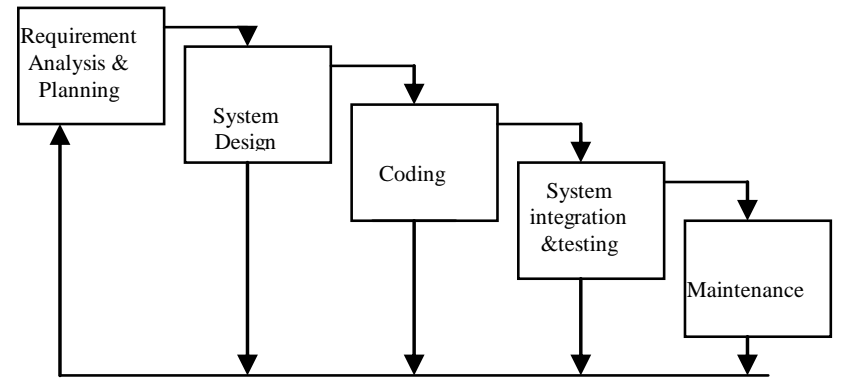

Figure 1: Software Development Life cycle phases

Firstly, in the requirement analysis and planning phase, the criteria of a good dairy recording system were first determined. Keeping in mind that a farmer has enough tasks in hand, the main objective of ICRAS $\odot$ was not to burden them with a complicated recording system, that is hard to understand and time consuming to handle. In other words, the system should be simple and effective. Hence, the first element taken into consideration was, a recording system should be useful, in terms, that the recorded data must have the prospect of producing fruitful information in the future [11]. Otherwise unnecessary data should be ignored. Next, the records must be maintained in a form that can be kept for a long time and undoubtfully transformed into information in the future. For an example, a farmer can choose to keep his records in a written or computerized form and decide the best form that can be kept for future analysis. Finally, the analyzed information should be able to guide the farmer to take actions or make decisions for future planning and development of his herd. Otherwise a recording system is not useful. These were the main guidelines and requirements used to develop ICRAS $\odot$.

There are different aspects in a dairy farm management that can be addressed in relation to their importance. In ICRAS $\odot$ three main elements were identified, which are the milk productivity, fertility, and health. Among these aspects, fertility and reproduction is the core element of a dairy farm operation. The reduction of fertility in dairy herds is one of the most crucial reasons affecting a farmer's profitability [12]. Reproduction losses often go unnoticed because they are indirect costs [13]. So, in order to overcome this problem, the first element that has to be taken into consideration is to maintain proper fertility records [13]. However, fertility records are rarely kept by small holders due to not knowing its importance. Thus, ICRAS $\odot$ introduces a simple fertility record keeping feature which is easy to be maintained and produces significant analysis results of an individual cow or the herd.

Recording milk production of each cow per lactation is also an important aspect in a dairy farm. The availability of continuous lactation records is the most important tool for efficient milk production, and can be a guide in proper feeding, breeding, and weeding out the low-producing and unprofitable cows [14]. This will also help the farmer to reduce the cost of production of his farm. In ICRAS $\odot$, an interface to record and store production per lactation is designed for individual cows which could help the farmer to evaluate his cow's performances.

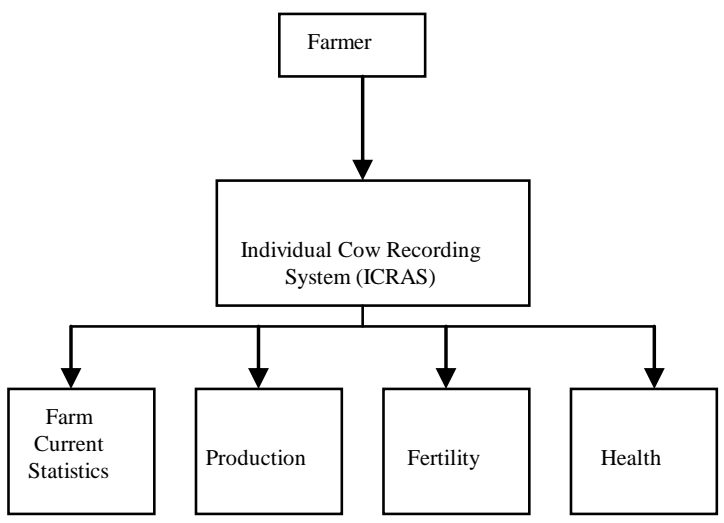

Figure 2: Four main modules in ICRAS@

The impairment of production efficiency is closely related to the changes in a cow's health especially in the areas of mastitis and reproduction. Health records of a cow will tell the farmer on when to repeat a treatment, and help him to know exactly how a disease has preceded, as well as the effectiveness of the given treatments. This information will be very useful in the future, to help recollect all the details. Apart from that, it will be also very useful for a new veterinarian, who has less information on the farm, to give appropriate advice. These reasons, was one of the motivations for ICRAS $\odot$ to have the health and treatment recording features.

\section{APPLICATION}

ICRAS $\odot$ was developed using the Microsoft Office Excel 2003. This powerful desktop application was chosen due to its ease of availability in the market where nearly $90 \%$ of personal computers are installed with it. Due to its widespread usage and the likeliness of the farmer to already have this installed on his computer, reduces the need to implement or purchase any 
new software with an expensive after sales support. Combined with its built-in Visual Basic for Applications (VBA) scripting language, a full-fledged programming language, made the development of ICRAS $\odot$ much easier and inexpensive. The VBA was used to program all the background analytical logics and to create the user-friendly interfaces. The development of ICRAS $\odot$ on the Microsoft Excel platform, made it to be a stand-alone application with a flexible reporting tool to efficiently analyze information from an existing desktop.

ICRAS( ) was architected to have four main interfaces, which are the individual cow record, herd fertility status, herd health status and farm dashboard. Whereas, the individual cow record have three sub-interfaces, which are the production data, treatment data and fertility data. Among the four main interfaces, the individual cow record interface has to be created for every cow in the farm, while the remaining three interfaces are for the observation of the whole herd status. Figure 3 shows the system architecture of ICRAS $\odot$.

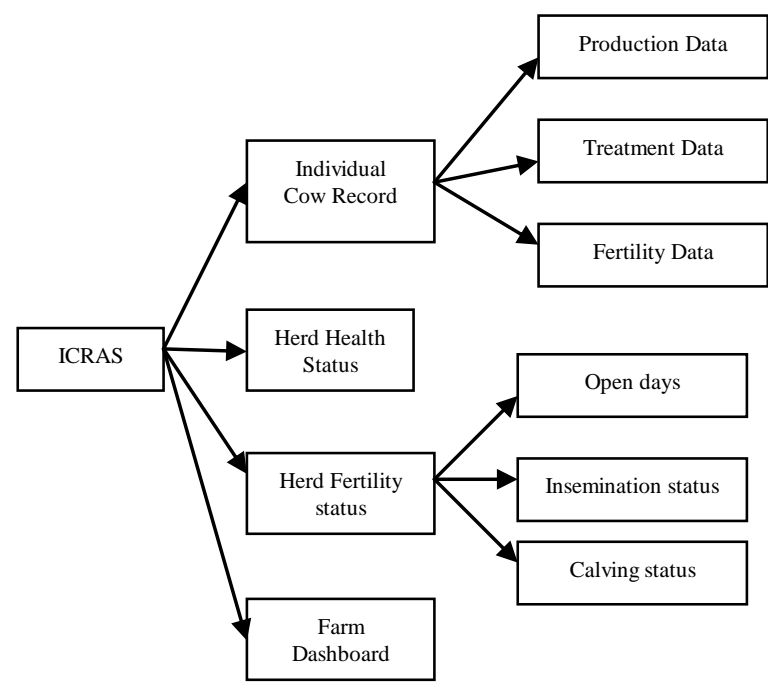

Figure 3: System architecture of ICRAS $\odot$

ICRAS $\odot$ was designed to follow a logical sequence of steps. The data input received from the farmers are processed and the results obtained are displayed for action to be taken by the farmer. The farmer has to first create an individual record for each cow in his farm, where each record should have a unique animal identification number (AIN), then all the modules has to filled up with input values, such as milk production, fertility status and health status. Next, the individual record has to be registered in the Farm Current Statistic module with reference to the AIN. Once the record is registered, the status and statistics of the cow will be dynamically updated based on the farm's latest data. Figure 4 depicts the logical flow of the system.

As mentioned in the previous section, each individual cow record interface has three sub-interfaces. In the production subinterface, the farmer has to insert manually the year of lactation, the last calving date, monthly production of milk in litres, dry date and days in milk. The system would calculate the total production per year and also per lactation. This will enable the farmer to observe the performance of his cow in terms of production.
Next, in the fertility sub-interface, the farmer has to insert last calving date, insemination date, mode of insemination and also the pregnancy detection date and status. The system would dynamically calculate the predicted heat observation date,

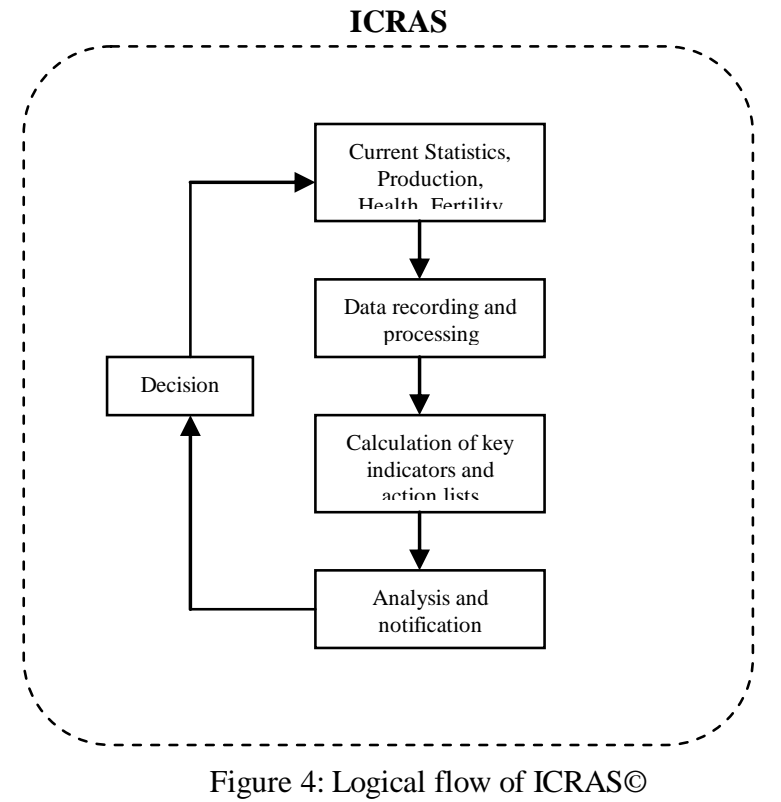

prediction calving date, open days (days not conceived since last calving), calving interval and the calving to conception rate.

The final sub-interface is the treatment records; the farmer has to input the treatment date, the next follow-up date, treatment, diagnosis and the status. The system would keep track of the next follow-up date and alerts the farmer. These interfaces are depicted in Figures 5, 6 and 7 respectively.

In order to demonstrate the benefit of this interface, the following scenario is explained. Imagine that a farmer has two cows, cow A001 and cow A002. Six weeks after calving, cow A001 produced around 20 litres of milk per day and has an impressive production per-lactation of 3600 litres, assuming that lactation consists of 6 months. Whereas, cow A002 produces only 13 litres per day, with a total production perlactation of 2340 litres. However, cow A001 and A002 has a calving interval of 3 years and 1.5 years respectively, refer Table 1. Intuitively, to evaluate both cows without proper records, the farmer might say that A001 is the finest milking cow since it produces the highest quantity of milk. But, his intuition is wrong since the calving interval of A002 is higher.

By using ICRAS $\odot$, the farmer could easily evaluate the performance of the cows by observing in the Production and Fertility sub-module, where the amount of milk produced and calving interval are available. Therefore, this example clearly depicts the importance of a recording system.

The next interface is the Herd Health Status. This interface gathers all the treatment follow-up dates which is due for the current month from all the Individual Cow Records. This interface will enable the farmer to keep track and monitor the herd health status. Refer Figure 11. 
Table 1. Example of Milk Production and Calving Interval for a Farm of Two (2) Cows.

\begin{tabular}{|c|c|c|c|}
\hline AIN & $\begin{array}{c}\text { Last Calving } \\
\text { Date }\end{array}$ & $\begin{array}{c}\text { Production/Lactation } \\
\text { (Litres) }\end{array}$ & $\begin{array}{c}\text { Calving } \\
\text { Interval } \\
\text { (Yrs) }\end{array}$ \\
\hline A001 & 1-Aug-2010 & 3600 & 3 \\
\hline A002 & 1-Aug-2010 & 2340 & 1.5 \\
\hline
\end{tabular}

Next is the Herd Fertility status interface. This interface has three sub-interfaces. Which are the Open Days, Insemination status and the Calving status. The Open Days sub-interface produces a list of cows which have more than 300 open days. This list will help the farmer to identify the animals which have reproduction problems or to conduct any fertility treatment programs. The Insemination status sub-interface will display a list of cows which are to pregnancy detection for the current month. This will assist the farmer to detect the number of cows which are pregnant or not pregnant for the current month. Apart from that, this interface will also help the farmer to plan any Artificial Insemination (AI) program to be conducted on his herd. The next sub-interface is the Calving status. This interface will provide the farmer with a list of cows which are due to give birth for the current month. This will aid the farmer to predict the number of calves that will be available and prepare all necessary facilities to accommodate the new comers. This interfaces can viewed in Figure 8, 9 and 10 respectively.

The next interface is the Farm Dashboard interface. This is the main interface of ICRAS $\odot$. From this interface the farmer will have the capability to view the key statistics of his herd. Such as, the total number of milking animals, dry animals (cows that are not producing milk), highest/lowest producer of the month, top producing cows, total herd production trend of the year, total cows due to calf, total cows due to be tested for pregnancies and the current status of individual cows. Critical decisions such as identifying the lowest performing animals in terms of milk production and fertility for culling could be easily made. This interface can be observed in Figure 12.

\section{CONCLUSION}

The work presented in this paper clearly demonstrates the importance of a farm recording system. The development of ICRAS@ $\odot$ with the usage of common softwares such as the Microsoft Excel 2003 proves that a simple and cost efficient computerized recording system could be easily implemented by small scale dairy farmers. The proposed system creates a new window in the recording practice of small-holders and therefore contributing to the development of the Malaysian dairy industry.

\section{ACKNOWLEDGMENTS}

I would like to thank the Dairy Industry Service Centre (PPIT), Department of Veterinary Services, Malaysia for providing their relentless support in the development of ICRAS@

\section{REFERENCES}

[1] Ministry of Agriculture \& Agro-Based Industry, Malaysia, "Information on Livestock", Agriculture Statistical Handbook, pp.134, 2008. [Online]. Available: http://www.moa.gov.my/html/themes/moa2_new/documen t/MaklumatUtamaTernakan.pdf. [Accessed July 23, 2010].

[2] H. J. Pharo, M. J. Sopian, M. Kamaruddin, M. A. Abu Hassan, P. F. Cheah, T. W. Choo, "Progress in the use of computerised recording systems in dairy cow monitoring and extension in Malaysia", Tropical Animal Health and Production. Vol 22(2), pp. 77-88, 1990.

[3] Research And Markets, "Malaysia Agribusiness Report Q1 2009”, pp.1-2, 2009. [Online]. Available: http://www.researchandmarkets.com/reports/1072230. [Accessed July 20, 2010].

[4] Department of Veterinary Services,Malaysia, "Annual Report 2008", pp.1-93,2008.

[5] Kevin Silver, "Dairy Records Management", Kosovo Cluster and Business Support Project report, pp. 1-18, 2006.

[6] M.G.G. Chagunda, A.C.M. Msiska, C.B.A.Wollny, H .Tchale, J .W.Banda, “An analysis of smallholder farmers' willingness to adopt dairy performance recording in Malawi. Livestock Research for Rural Development", Livestock Research for Rural Development, vol 18 (5), 2006. [Online]. Available: http://www.lrrd.org/lrrd18/5/chag18066.htm. [Accessed July 19, 2010].

[7] M. Taylor, D. Hoag, M.Owen, "Computer literacy and use”, Journal Ext., vol 29 (4), pp.11-13, 1991.

[8] A.A. Razaq, Z. A.Norhasni, B. Jamaludin, P.S. Wai, "Computer Usage and Achievement among Adults in Rural Area Malaysia", Journal of Social Sciences, vol 5 (1), pp. 1-8, 2009.

[9] Nova Scotia Department of Agriculture and Fisheries, Canada, "Record Keeping", Dairy Calf 4-H Leader Resource Manual, Section 14, 2004. [Online]. Available:

http://www.gov.ns.ca/agri/4h/manuals/dairy/section14.pdf. [Accessed July 20, 2010].

[10] Shah Newaz Alam, "Waterfall Model Advantages and Disadvantages", Buzzle.com. [Online]. Available: http://www.buzzle.com/articles/waterfall-modeladvantages-and-disadvantages.html. [Accessed July 18, 2010].

[11] P G Stewart Cedara Agricultural Development Institute, "Dairy Farm record keeping". [Online]. Available: http://agriculture.kzntl.gov.za/portal/AgricPublications/Pro ductionGuidelines/DairyinginKwaZuluNatal/DairyFarmRe cordKeeping/tabid/245/Default.aspx. [Accessed July 19, 2010]. 
[12] F.J. Mulligan, L. O’Grady, V.P. Gath, D.A., Rice and M.L. Doherty, "Nutrition and fertility in dairy cows", Irish Veterinary Journal, Vol 60(5), pp.311-316, 2007.

[13] J.F. Keown, "How to Estimate a Dairy Herd's Reproductive Losses", Dairy B-9 Breeding \& Reproduction, University of Nebraska-Lincoln, 1986. [Online]. http://digitalcommons.unl.edu/extensionhist/538. [Accessed July 20, 2010].

[14] R. E. Hodgson, "Keeping Production Records on Dairy Farms Is the Key to Greater Efficiency and Profits", Journal of Dairy Science , Vol. 40(2), pp.200-202, 1957.

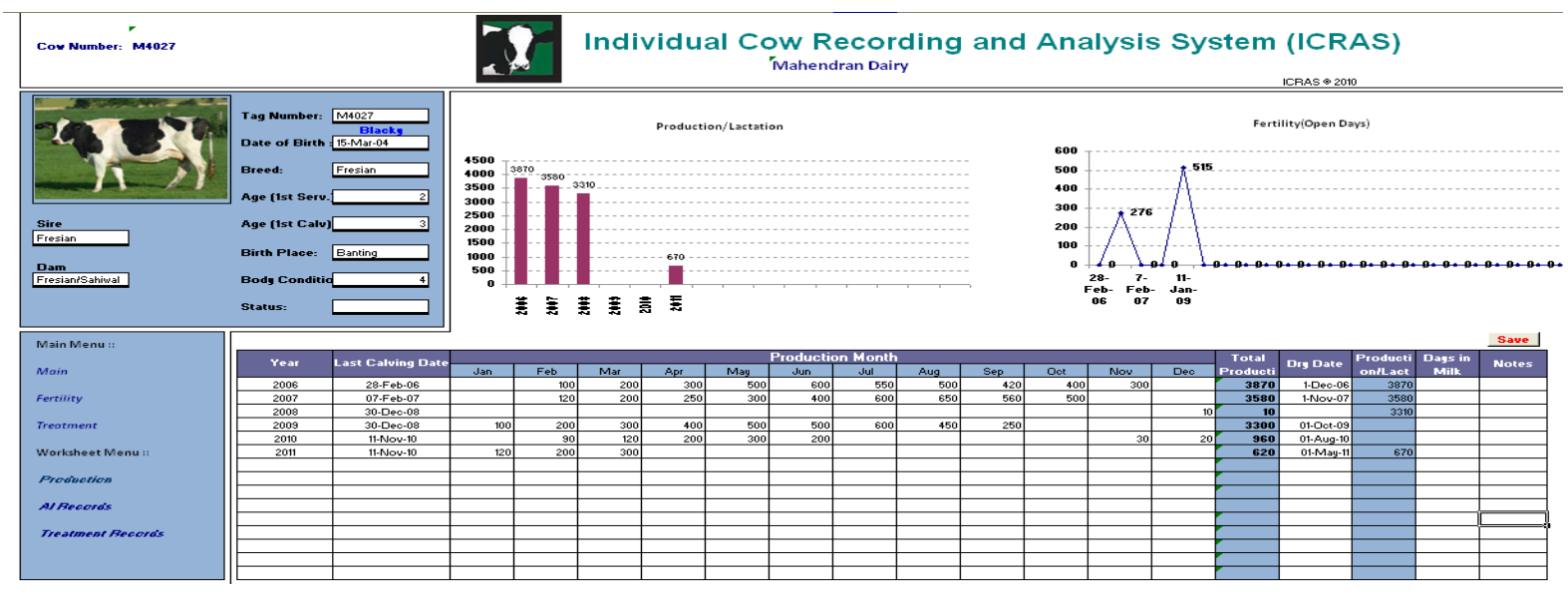

Figure 5: Individual Cow Record Interface (Production)

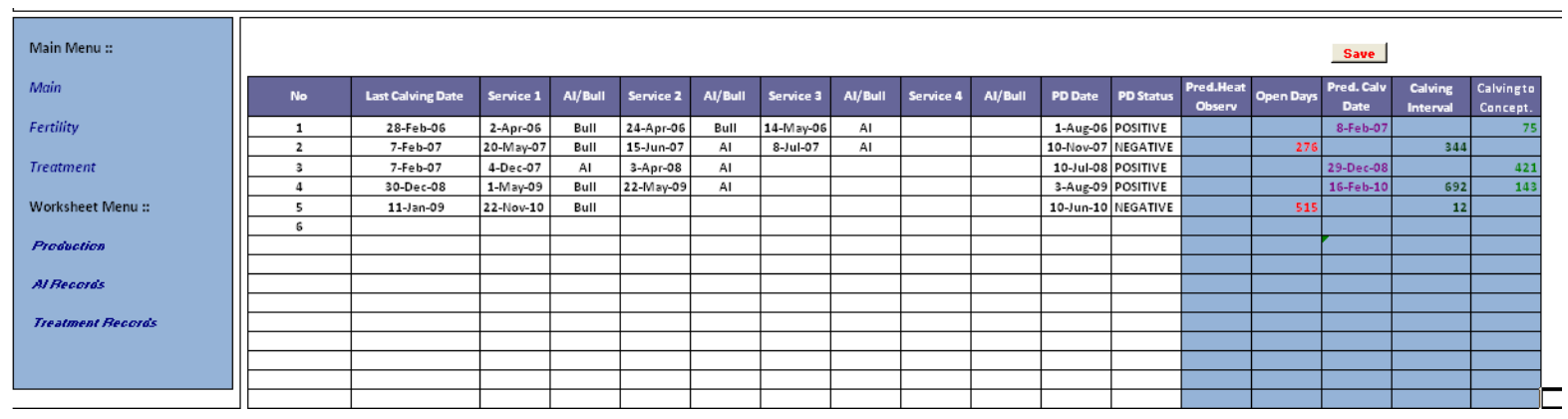

Figure 6: Individual Cow Record Interface (Fertility)
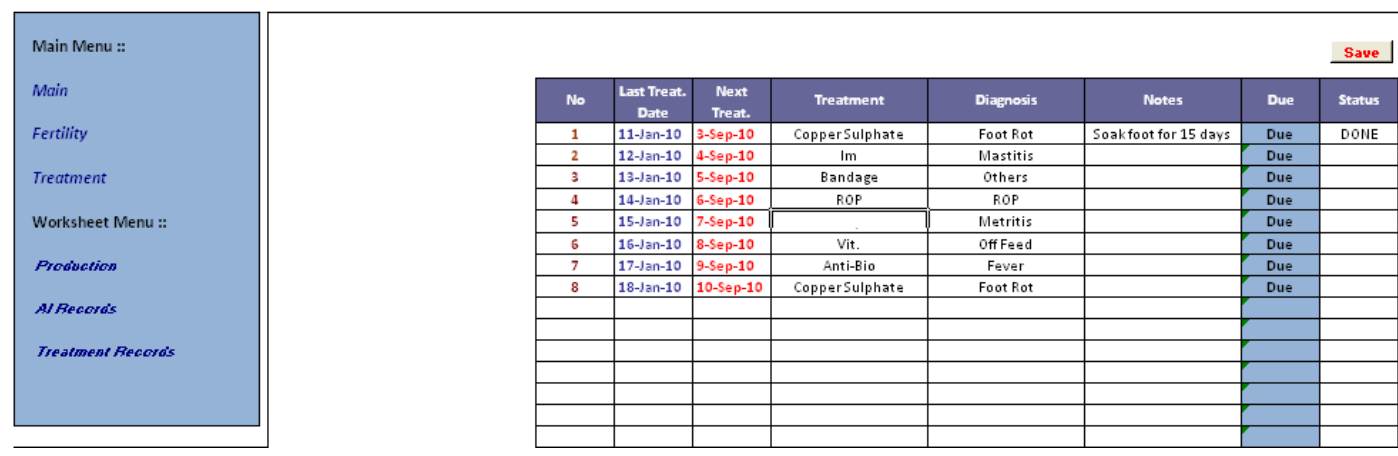

Figure 7: Individual Cow Record Interface (Treatment) 


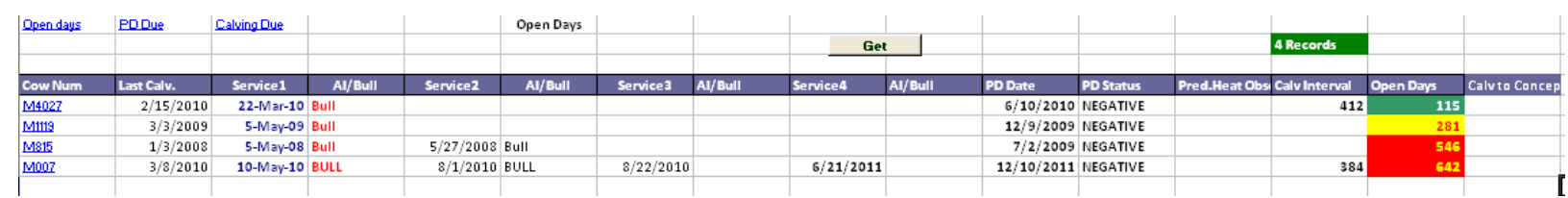

Figure 8: Herd Fertility Status Interface (Open Days)

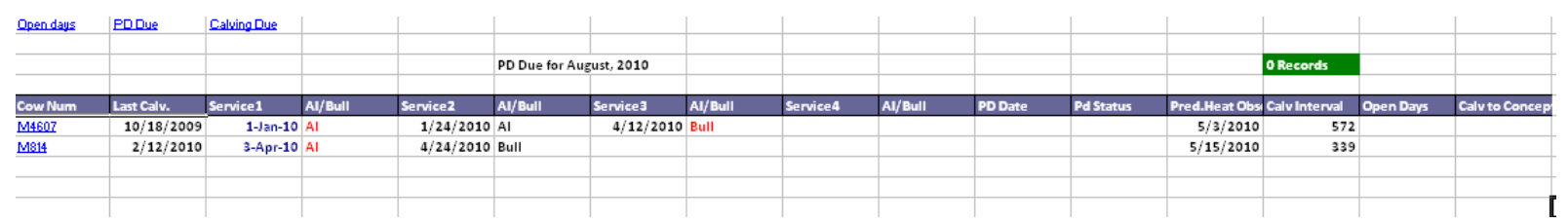

Figure 9: Herd Fertility Status Interface (Insemination Status)

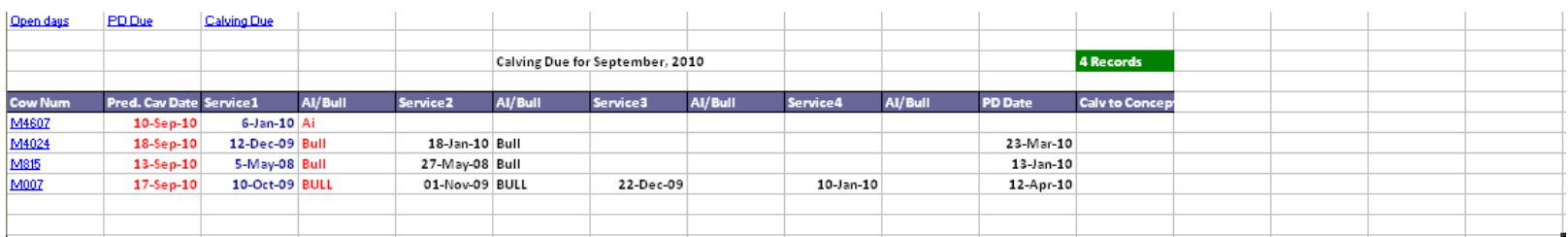

Figure 10: Herd Fertility Status Interface (Calving Status)

\begin{tabular}{|c|c|c|c|c|c|c|c|c|}
\hline & & & & & \\
\hline
\end{tabular}

Figure 11: Herd Health Status interface

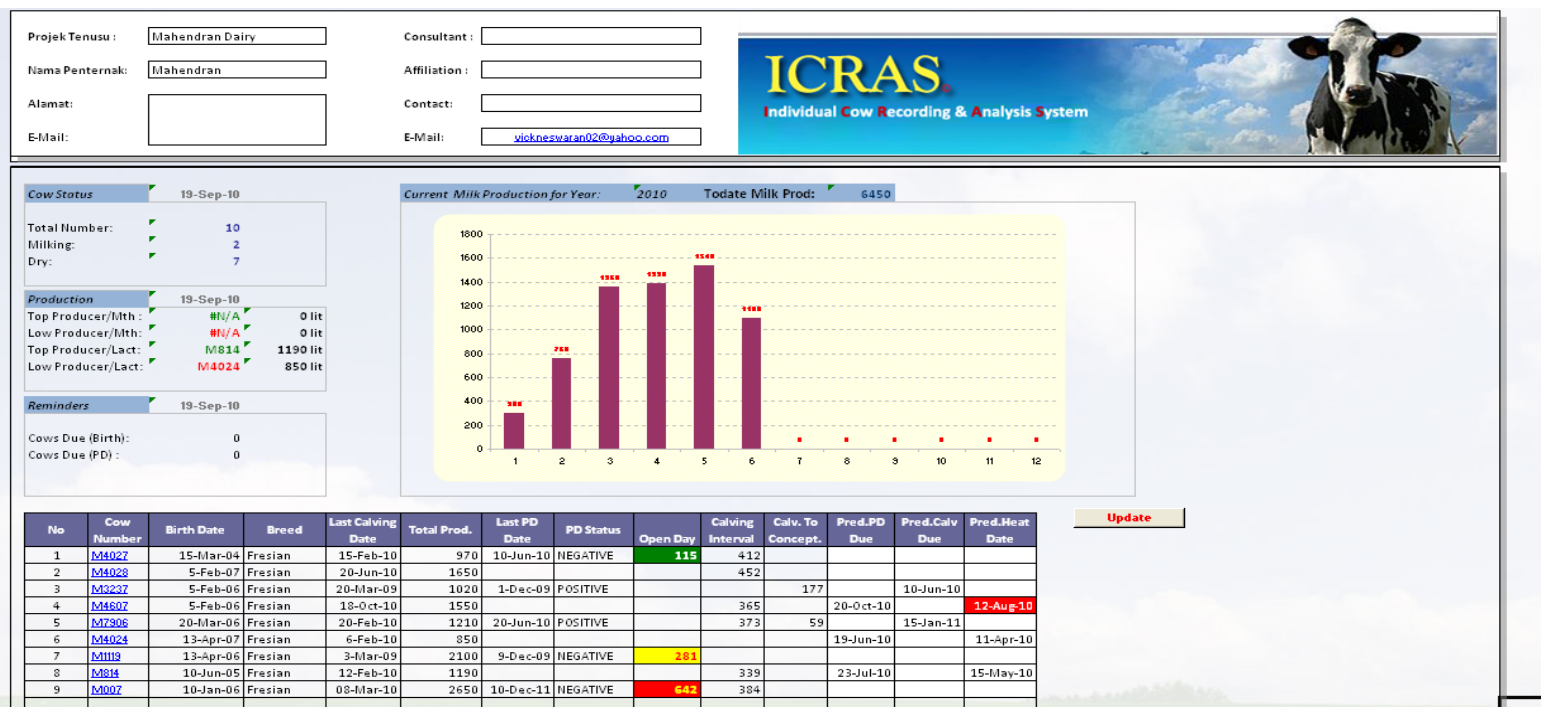

Figure 12: Farm Dashboard interface 